\title{
Sustainability and Optimization of Supply Chains: a Literature Review
}

\author{
Zlatan Mujkić \\ Lappeenranta University of Technology, \\ School of Business and Management, Lappeenranta, Finland \\ E-mail: zlatan.mujkic@lut.fi (Corresponding Author) \\ Ardian Qorri \\ Lappeenranta University of Technology, \\ School of Business and Management, Lappeenranta, Finland \\ E-mail: Ardian.Qorri@lut.fi
}

\author{
Andrzej Kraslawski \\ Lappeenranta University of Technology, \\ School of Business and Management, Lappeenranta, Finland \\ Technical University of Lodz \\ Faculty of Process and Environmental Engineering, Lodz, Poland \\ E-mail: Andrzej.Kraslawski@lut.fi
}

\begin{abstract}
Sustainability of supply chains (SCs) and supply chain optimization is a topic of increasing interest in academia and industry. Although several authors have studied various aspects optimization and sustainability of SC, there is still a gap in understanding sustainable development of SCs. The aim of this study is to bridge this gap and to better understand interdependencies between economic, environmental and social dimensions of sustainability. To fulfill the research objective, this study examines 50 peer-reviewed articles published literature in the field of sustainable SCs and SC optimization. Selected papers used mathematical modeling techniques (optimization) as research methodology combined with one or more dimensions of sustainability. Findings of this work indicate that there are several SC optimization models addressing all three dimensions of sustainability simultaneously, and social dimension of sustainability is the least studied aspect. Furthermore, an application taxonomy of mathematical modeling approaches used in sustainable SCs is provided. Future research should shift the focus from models dealing primarily with economic and environmental dimensions towards more balanced models that include all three sustainability aspects. This paper enhances understanding how was sustainability principles are incorporated into mathematical models for SC optimization, and provides SC optimization models with pertinent sustainability indicators.
\end{abstract}

Keywords: sustainability, supply chains, mathematical modeling, optimization, literature review

\section{INTRODUCTION}

Increased globalization and fierce competition are forcing companies to be more efficient and flexible. Companies should match demanding economic objectives and at the same time operating in a sustainable manner as well as they should meet consumer needs (Barbosa-Póvoa,
2012). Sustainable development of SCs is a crucial part of any business and efficient SCs are imperative for highquality products and for on-time delivery. Therefore, operating SCs in a sustainable manner is a complex endeavor, whose complexity depends on the number of echelons, materials, and services within SCs (BarbosaPóvoa, 2014). According to Papageorgiou (2009), modern industrial enterprises consist of multiple operations, sites and facilities, which can be located in different countries, regions, or parts of the world. The author further argues that different activities of SCs including planning, cooperation and coordination, and responsiveness to customer demands need to be considered to ensure effectiveness, competitiveness, sustainability, and growth of SCs.

Supply chain management (SCM) involves movement of material and services from upstream to downstream operations of SCs. In today's global and competitive environment, SCM and decision-making process arises both from strategic and operational standpoints (Papageorgiou, 2009). According to Ganeshan and Harrison (1995),decision-making process and SCM can be divided into:1) location, 2) manufacturing, 3) backlog, and 4) logistics while operational, tactical and strategic decisions are present in all these levels. The goal of SCM is to systematically integrate suppliers, manufacturers and consumers for goods and services to be manufactured and distributed in the correct place, accurate time, and in the right amount, while simultaneously ensuring maximum SC performance (Ruiz-Femenia et al., 2013). A simplified SC network structure is presented in Figure 1. Usually, SCs are characterized by five levels (echelons): 1) raw material extraction, 2) processing of raw material into final products, 3) storing products, 4) delivery of products to retailers, and 5) purchasing of final products at retail outlets by consumers. 


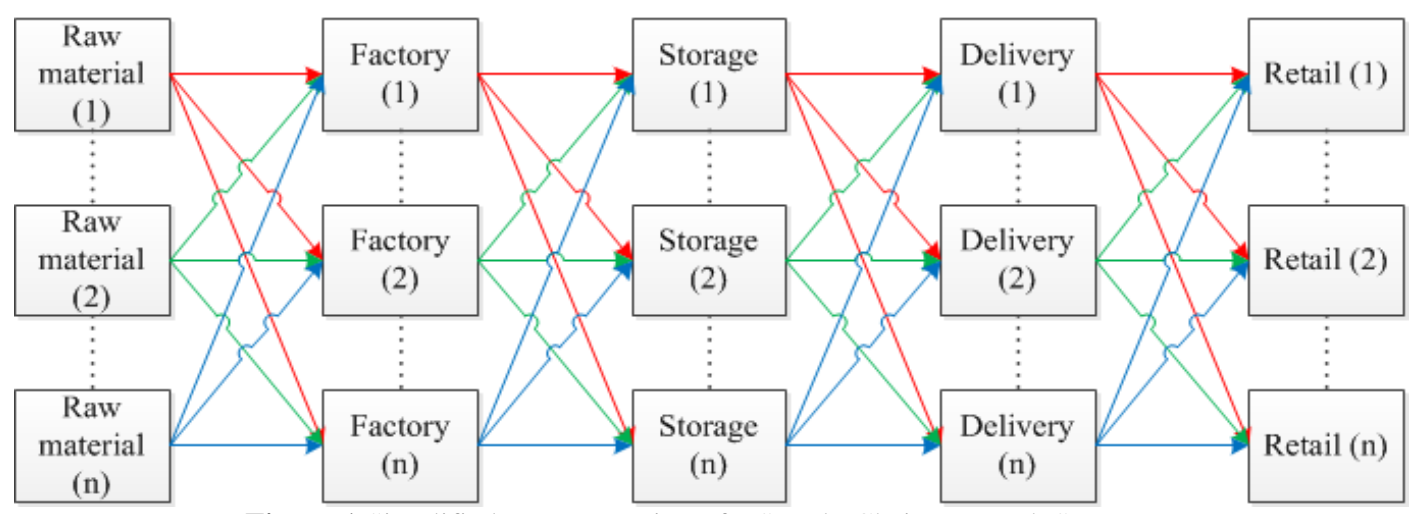

Figure 1 Simplified Representation of a Supply Chain Network Structure.

SCs players'interest in sustainability is growing and is becoming a major focus of SCM. Sustainable development research of SCs is based on principles, which include economic, environmental and social aspects. Many research papers have been published on the topic of sustainable SCs and SCM including qualitative and quantitative research approaches. While there are several published review papers dealing with economic and environmental aspects of sustainability, there are few review papers dealing explicitly with all three dimensions of sustainability. Furthermore, there is lack of review papers, where sustainability and optimization of SCs is integrated with SCM and decision making from economy, environment and society standpoint. Therefore, the objective of this paper is to bridge this gap.

In other words, the main idea of this paper is to review scientific papers dealing with issues in SCs and SCM that encompass either one or more dimensions of sustainability, namely: economic, environmental or social. All reviewed papers incorporated mathematical models including linear and nonlinear with integer and mixed-integer variations, and binary decision variables for selection of SCs network structure topology. Papers selection process is based on following research questions: 1) which sustainability dimensions are considered in each article? 2) Which sustainability aspects of SC are covered by mathematical models? 3) What objectives and how mathematical models for sustainable SCs are formulated?

This paper is structured as follows:Section2describes the methodology and criteria used for selection of articles; Section 3,discussesdimensions of sustainability and their integration in SCs; Section 4 depicts different methods and mathematical modeling formulation used in SC optimization. Material reviewed is divided based on singlecriteria and multi-criteria decision-making models. In addition, applications of mathematical models in different areas of sustainable SCs and are provided. Finally, Sections 5 and 6 discuss the findings, future research directions and conclusions of this paper.

\section{REVIEW METHODOLOGY}

\subsection{Paper Selection Process}

This study follows the guidelines proposed by Rowley and Slack (2004), which include following steps:

- Searching and selection of papers

- Extraction of relevant information

- Organizing literature review
- Building and expanding the bibliography and

- Writing literature review.

An extensive search of relevant literature between 2000 and 2017 was done to gather relevant peer-review papers on literature of sustainable SCs and SC optimization. This time period was selected as most papers have been published after 2000(Seuring and Müller, 2008).

The searching process for peer-reviewed papers was initiated from the scientific research database-Science Direct (http://www.sciencedirect.com). Science Direct was selected as main source of peer-review papers for two reasons. First, Science Direct database is indexing majority of influential scientific journals, especially technical journals. Second, Papers covering sustainability and optimization of SCs are mostly published in technical journals.

The following keywords were used in searching process: supply chain, supply chain optimization, and sustainable supply chain. These keywords were used in a Boolean search in combination with following terms: mathematical modeling, green supply chain, sustainability, environmental sustainability, and social sustainability. Backtracking of papers for earlier sources and forwardtracking for relevant sources to find papers that we could not locate using keywords search, were also implemented.

Papers that did not fulfill all following criteria were not selected for this review: 1) article should be written in English and published in a peer-reviewed journal; 2) paper should use mathematical modeling (optimization) as research methodology for decision making; 3) objective functions or constrains of the models should consider explicitly economic, environmental, or social aspects of sustainable SCs.

Based on this process we selected 50 articles, which consist the final sample of this study. After this phase, we extracted relevant information from each selected study. This information is broadly divided into two main categories: SC sustainability (Section 3)and mathematical modeling (optimization) (Section 4), and these categories are further divided into several sub-categories.

\subsection{Distribution of papers by publication source and year}

The selected papers were organized into several different categories according to research questions of this study. First categorization was done based on the sustainability dimensions, namely economic, 
environmental, and social sustainability. Second categorization classified papers based on the indicators and/or objective functions of given mathematical models. Third categorization was done based on the mathematical modeling formulation used in the reviewed papers, and fourth categorization classified papers based on applications of optimization models in different areas of SCs.

Several review papers are published in the last two decades that address various aspects of SCs, e.g., SC management Croom et al. (2000), green aspects of SCs Srivastava (2007), global SC models and design Meixell and Gargeya (2005), and multi-objective optimization Trisna et al. (2016).Besides, review papers related to SC optimization and sustainability are listed in Table $\mathbf{1 .}$

From Table $\mathbf{1}$ it is evident that there has been extensive research interest in SC optimization and various topics connected with SCs and sustainability. Based on that, it is noticeable that SCs have received significant attention from research community, and research interest on this area seems to continue in the future, as the next figure indicates.

Figure 2 presents distribution of reviewed papers over the time period of seventeen years. Clearly, there search interest in the field of sustainable SCs has been increasing steadily over the years, and this trend is notably oriented towards environmentally and socially sustainable SCs. In addition, there is also increasing interest on optimization related problems of SCs.

Publication source of selected articles is shown in Figure 3. It is clear that there are many journals publishing papers related to sustainability and optimization of SCs. The highest number of papers per journal is in "Journal of
Cleaner Productions" and "Computer and Industrial Engineering". While the total number of journals is 22, around half of them have published only one paper included in our sample.

Furthermore, from Figure 3 it is evident that the reviewed papers are published in wide variety of journals, which indicated that sustainability and SCM has gained attention from wide variety of research fields.

\section{SUSTAINABILITY OF SUPPLY CHAINS \\ 3.1 Dimensions of Sustainability}

Sustainable development of SCs includes economic, environmental and social aspects of sustainability within SCs (Giddings et al., 2002), while keeping SC partner communications at high level at any given moment (Burritt and Schaltegger, 2014). The term three dimensions of sustainability, sometimes referred to as the triple bottom line, was first used by Elkington (2001). In recent years, sustainability is becoming an important part of everyday decision-making process of enterprises within local and global SCs. Furthermore, as mentioned before sustainability is generally divided into three different aspects, based on the area of interest: economic sustainability, deals with costs and financial stability of SCs; environmental sustainability, deals with the impact of the SCs on the environment; and social sustainability, studies the impacts of SCs on societies, human well-being, and stakeholders (Bhinge et al., 2015).

Table 1 Chronological List of Previous Literature Reviews on Various Topics in SCs.

\begin{tabular}{|c|c|}
\hline Authors & Focus \\
\hline Min and Zhou (2002) & Challenges and difficulties associated with supply chain design and modeling. \\
\hline Grossmann (2004) & $\begin{array}{l}\text { Industry trends in supply chains including product discovery and design, supply chain } \\
\text { optimization and global life cycle assessment. }\end{array}$ \\
\hline Shah (2005) & Supply chain network design, planning and scheduling with industrial applications and modeling. \\
\hline Papageorgiou (2009) & $\begin{array}{l}\text { Mathematical modeling for advance decision making at strategic and operational level of process } \\
\text { industries. }\end{array}$ \\
\hline Barbosa-Póvoa (2012) & Optimization and sustainability in supply chains of process industries. \\
\hline Grossmann (2012) & $\begin{array}{l}\text { Deterministic and non-deterministic models, economic and environmental impacts of supply } \\
\text { chains. }\end{array}$ \\
\hline Basnet and Seuring (2014) & Supply chain strategies of product demand. \\
\hline Barbosa-Póvoa (2014) & $\begin{array}{l}\text { Design of supply chains in process industry with consideration of uncertainties, risk and } \\
\text { sustainability. }\end{array}$ \\
\hline Eskandarpour et al. (2015) & Multi-objective optimization of supply chain network design and sustainability. \\
\hline Trisna et al. (2016) & Techniques and modeling approaches used for multi-objective optimization of supply chains. \\
\hline
\end{tabular}

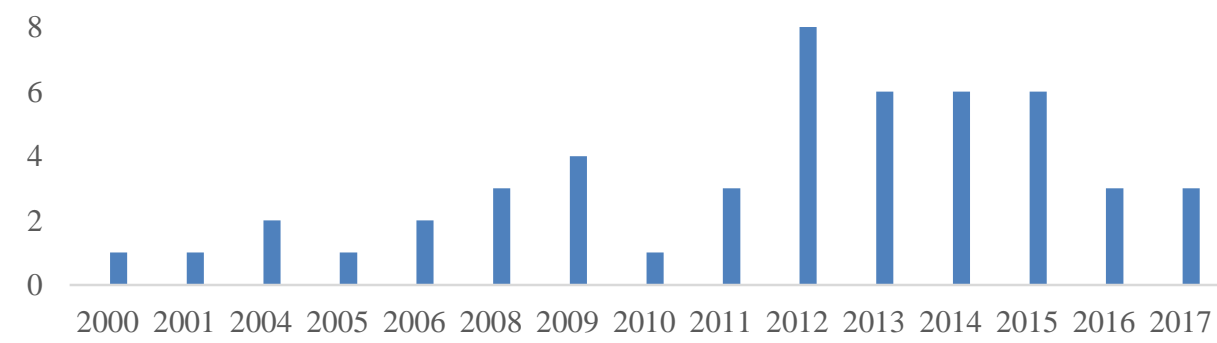

Figure 2 Number of Reviewed Papers Published per Year for the Period Covered by the Study. 


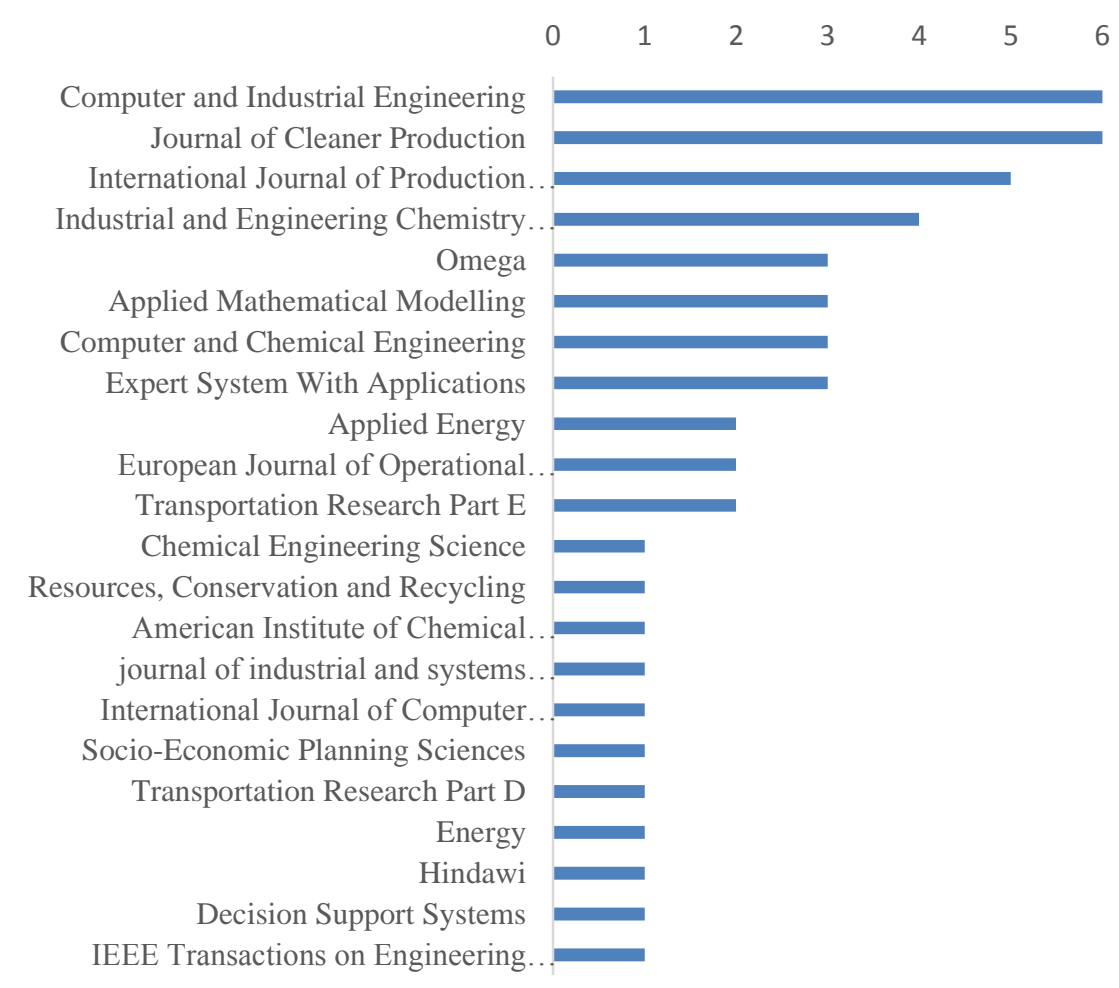

Figure 3 Distribution of Reviewed Papers per Journal.

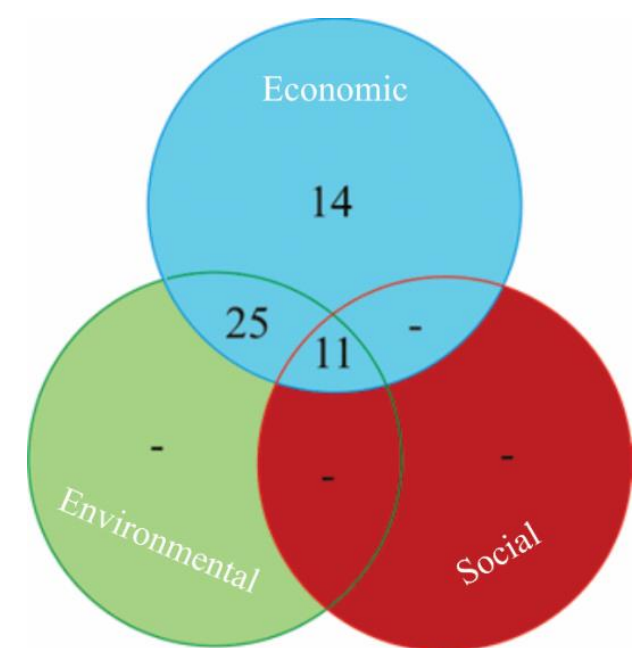

Figure 4 Distribution of Sustainability Dimensions by Reviewed Papers.

In Figure 4 dimensions of sustainability are presented, where the blue, green and red colors represent economic, environmental and social dimensions of sustainability, respectively. Half of the reviewed papers studied both environmental and economic dimensions of sustainability. While none of the articles selected have studied explicitly social and economic dimension. Reason for this is because most papers studied sustainability issues related to industry, which has enormous environmental impact. The rest of the papers (11) have included all three dimensions of sustainability into their models. The economic dimension is studied in all aspect of SC sustainability (Garcia-Herreros et al., 2014; Lababidi et al., 2004; Oliveira et al., 2013) while environmental dimension of sustainability is addressed in half of the papers reviewed (Hugo and Pistikopoulos, 2005; Lee et al., 2009; Varsei and Polyakovskiy, 2017). The least studied subject is social sustainability, although, interestingly, when the social dimension is studied, this is done together with other two dimensions (Alçada-Almeida et al., 2009; Mota et al., 2015; Varsei and Polyakovskiy, 2017).

Table 2 presents different SC mathematical models and formulations applied in sustainability dimensions. Most authors adopted mixed MILP as the modeling approach. While NLP and mixed integer nonlinear programming are the least used approaches.

Table 2 SC Modeling Approaches Used in Different Sustainability Aspects.

\begin{tabular}{|c|c|c|c|c|c|c|c|}
$\begin{array}{c}\text { Modeling } \\
\text { approach } \\
\text { Sustainability }\end{array}$ & LP & MILP & NLP & MINLP & GA & FA & HA \\
\hline Economic & 3 & 24 & 1 & 3 & 7 & 4 & 8 \\
\hline Environmental & 2 & 22 & - & 2 & 5 & 3 & 2 \\
\hline Social & - & 9 & - & - & 2 & - & - \\
\hline
\end{tabular}


* Notes: LP - linear programming; MILP - mixed integer linear programming; NLP - nonlinear programming; MINLP - mixed integer nonlinear programming; GA generic algorithm; FA - fuzzy algorithm; HA - hybrid algorithm.

\subsubsection{Economic Dimension of Sustainability}

According to Harris (2000), economic sustainability can be defined as: "An economically sustainable system must be able to produce goods and services on a continuing basis, to maintain manageable levels of government and external debt, and to avoid extreme sector imbalances which damage agricultural or industrial production. "While economic sustainability has inherently positive impacts, growth requires an increased flow of materials and energy. Therefore, growth tend negatively contributes to depletions of resources, making balancing between economic and other aspects of sustainability an imperative (Al Ansari, 2012). Economic growth and SC sustainability generally involve design and operation of complex networks of SC structures, which include the cost of investment, logistics, storing, and distribution of goods(Garcia-Herreros et al., 2014).

Table 3 Indicators Used for Economic Sustainability of SCs.

\begin{tabular}{|c|c|c|c|}
\hline Sustainability & Decision level & Indicators & Number of times used \\
\hline \multirow{12}{*}{ Economic } & \multirow{6}{*}{ Strategic } & Profit b & 7 \\
\hline & & Cash flow ${ }^{a, b}$ & 6 \\
\hline & & Delivery lead time $a, b$ & 5 \\
\hline & & Customer satisfaction ${ }^{b}$ & 2 \\
\hline & & Trade level a,b & 1 \\
\hline & & Budget variance ${ }^{a, b}$ & 1 \\
\hline & \multirow{3}{*}{ Tactical } & Total costs a,b & 32 \\
\hline & & Capacity utilization ${ }^{b}$ & 3 \\
\hline & & Production effectiveness $\mathrm{a}, \mathrm{b}$ & 1 \\
\hline & \multirow{3}{*}{ Operational } & Demand uncertainty ${ }^{a}$ & 5 \\
\hline & & Product quality ${ }^{b}$ & 1 \\
\hline & & Percentage of defects ${ }^{b}$ & 1 \\
\hline
\end{tabular}

Source: ${ }^{\mathrm{a}}$ Gunasekaran et al. (2001); ${ }^{\mathrm{b}}$ Tajbakhsh and Hassini (2015)

Table 4 Indicators Used for Environmental Sustainability of SCs.

\begin{tabular}{|c|c|c|c|}
\hline Sustainability & Indicators & Categories & Number of times used \\
\hline \multirow{29}{*}{ Environmental } & \multirow{5}{*}{ Eco-indicator 99} & Damage to human health & 4 \\
\hline & & Damage to eco-system quality & 3 \\
\hline & & Damage to resources & 2 \\
\hline & & Global warming potential & 1 \\
\hline & & $\mathrm{CO}_{2}$ emission & 2 \\
\hline & \multirow{2}{*}{ ReCiPe 2008} & Resource Depleted & 1 \\
\hline & & Pollution & 1 \\
\hline & \multirow{4}{*}{ Impact 2002+ } & Human health & 2 \\
\hline & & Ecosystem quality & 2 \\
\hline & & Climate change & 2 \\
\hline & & Resources & 2 \\
\hline & \multirow{4}{*}{ EcoCosts } & Depletion of natural resources & 1 \\
\hline & & Effect on ecosystem & 1 \\
\hline & & Effect on Human health & 1 \\
\hline & & Global warming potential & 1 \\
\hline & \multirow{2}{*}{ Global Warming Potential } & GHG emission & 4 \\
\hline & & Carbon footprint & 1 \\
\hline & \multirow{12}{*}{ Non-aggregated Indicators } & Pollution & 1 \\
\hline & & $\mathrm{CO}_{2}$ emission & 7 \\
\hline & & $\mathrm{NO}_{2}$ emission & 1 \\
\hline & & CO emission & 1 \\
\hline & & Volatile organic compounds & 1 \\
\hline & & Water usage & 1 \\
\hline & & Green appraisal scores & 1 \\
\hline & & Carbon trading & 2 \\
\hline & & New technologies & 1 \\
\hline & & New material for products & 1 \\
\hline & & Water quality & 1 \\
\hline & & Fossil fuel consumption & 1 \\
\hline
\end{tabular}


Economic indicators, shown in Table 3, are categorized based on decision impact and they are divided into three levels (Tajbakhsh and Hassini, 2015).

- Strategic decision in SCs deal with long-term impacts of SCs (e.g., network structure, facility location, supplier selection).

- Tactical decisions in SCs deal with production, logistics, and suppliers.

- Operational decisions in SCs are focused on material, energy flow and operation, fulfilling the demand.

In this work, we identified 14 papers dealing exclusively with economic sustainability. However, in recent years there is a tendency, where scholars and researchers are shifting focus from purely economic sustainability models towards green and sustainable SCs. Furthermore, there are many review papers focusing only on economic sustainability modeling in SCs (Meixell and Gargeya, 2005; Melo et al., 2009; Vidal and Goetschalckx, 1997).

While many economic performance measurement indicators are available (see Table 3 ), the majority of papers used cost minimization as an objective function. Furthermore, it is commonly presented as a single objective function with various cost incorporated into it. Most papers that incorporated exclusively economic objective functions into mathematical models are done through network structure design. In contrast, profit and cash flow maximization have received less attention from researchers. This is surprising since businesses are mostly oriented towards profit maximization.

\subsubsection{Environmental Dimension of Sustainability}

During the last two decades, environmental sustainability has gained wide attention from society and this changed context also within academic circles. Environmental sustainability is usually considered within economic aspects of SC through multi-objective optimization (Ruiz-Femenia et al., 2013). Although many attempts over the years have been made, a consensus on the potential environmental impacts that need to be considered for minimization is lacking. Therefore, in best-case scenarios, mathematical models should optimize multiple impact categories. However, due to the nonlinearity and increased complexity of such models, these problems are hard to solve in reasonable computer time (Kostin et al., 2015).

According to Tognetti et al. (2015) implementation of environmental sustainability in SCs has been done in two ways: green design and green operation. Green design in corporate eco-design principles into network structures such as: closing the SC loop, and reverse logistics. Green operation involves recycling, waste management, green manufacturing, and remanufacturing. Table 4 shows that there is a wide variety of environmental indicators used in the reviewed literature.

Furthermore, most indicators are measuring direct impact of SC activities to the environment (e.g., gases emission, global warming, climate change), while fewer indicators measure long-term impacts (e.g., resource depleted, effect on ecosystem, water quality). Environmental indicators are commonly combined with economic and sometimes with social indicators in multiobjective mathematical models.

\subsubsection{Social Dimension of Sustainability}

Our results show that less research has been done on social dimension of sustainability, primarily due to the difficulty of quantifying social indicators (Mota et al., 2015). The integration of social sustainability with two other dimensions in SCs, leads to complex decision-making problems (Miret et al., 2016).

The GRI reporting guideline (GRI, 2014) divides social dimension into four categories: labor practices and decent work, human rights, society, and product responsibility. These categories are further divided into subcategories: labor practice and decent work is divided into 16 sub-categories, human rights into12 sub-categories, society into 11 sub-categories, and product responsibility into 9 sub-categories. Table 5 divides social indicators into two categories: indicators based on GRI, and non-GRI indicators. The majority of authors studied indicators related to employment (e.g., job created), while human rights, society and product responsibility are less investigated.

\subsection{Sustainable SCs Measurement and Assessment}

According to Ness et al. (2007), to develop sustainability, goals have to be identified and SC performance has to be measured. They further claim that there are many challenges facing the scientific community that hamper the development of reliable and efficient assessment tools. However, over time, the number of tools for measurement and assessment of sustainability has steadily grown. Some of the most used tools are Life Cycle Cost (LCC), Life Cycle Assessment (LCA) and Social Life Cycle Assessment (S-LCA), which can be used for measuring and assessing economic, environmental and social sustainability performance of SCs.

LCC is a method, which can be used to measure investment, operating costs etc., during a product's lifecycle. Economic sustainability is considered mostly for minimizing investment costs at distribution centers, transportation costs from distribution centers to the consumer, other costs (e.g., transportation, investment) from factories to distribution centers, and costs of storing materials in distribution centers (Garcia-Herreros et al., 2014).

The most commonly used and most developed tool for measuring environmental impact is LCA, which has been used in various forms to evaluate the impact of goods or services on the environment (Ness et al., 2007). Over the life cycle, products (goods and services) not only serve various purposes but also have different impacts upon raw material depletion and environmental pollution. The LCA method was created to help assess impacts on raw material depletion and environmental pollution (Wolf et al., 2012). There is still no consensus as to which indicators should be used, but it is generally accepted that environmental impact should be evaluated over the entire lifecycle of a product. Furthermore, LCA can be described as a quantitative method/tool for environmental assessment of goods, 
services or activities related to goods or services, "from cradle to grave" and in closed loop SCs-from cradle to grave and to cradle. Likewise, LCA can be used to assess the impacts on land, water, and air over the entire life cycle of goods and services (Ruiz-Femenia et al., 2013).

S-LCA is a similar method to LCA, which is used for assessment of the social and socio-economic impacts of goods and services, which can have positive or negative impacts on society, during their life cycle, and the approach consists of impact evaluation at every SC level: material extraction, processing and delivery of final product for open loop SC, reuse and recycling for closed loop SC and at the end of life cycle disposal (Benoît, 2010).

\section{SUPPLY CHAIN OPTIMIZATION AND SUSTAINABILITY}

According to Papageorgiou (2009), many different formulations and approaches of mathematical models are used in SC optimization. The most common approaches are mathematical programming, simulation, or a combination of both methods. Their application depends on the problem to be solved. Mathematical programming and mathematical modeling is usually used for optimization of decisions that involve new configurations, with combined aspect of dynamics and structure of operations such as SC network structure design. Whereas simulation models consider detailed dynamic operations of a known network structure with an operation uncertainty. Simulation modeling can be used to assess SC performance for a known configuration.

In the second half of the $20^{\text {th }}$ century, optimization has become a widespread technique, in areas such as chemical and process engineering, logistics, economics, and SC design (Sahinidis, 2004). Any "design" of a SC usually involves tradeoffs between conflicting objectives and, from the sustainability perspective, between economic, environmental and social objectives. Consequently, sustainable development and multi-criteria optimization in SC network design is an interesting topic worthy of study (Wang et al., 2011). Multi-objective optimization is widely applied to different decision-making problems and the implementation of optimization in decision making has seen growing interest in recent years (Jamshidi et al., 2012). SC network design can be divided into two design types, namely, open loop networks and closed loop networks where the reverse flow is incorporated (Nurjanni et al., 2017).

The following sections 4.1 and 4.2 describe the main contributions of the reviewed papers. These contributions are grouped into several categories in Table 6, Table 7. Table 6 presents papers that cover single criteria optimization models. Table 7 presents articles that use multi-criteria optimization models.

Table 5 Indicators used for social sustainability of SCs.

\begin{tabular}{|c|c|c|c|}
\hline Sustainability & Indicators level & Indicators & Time used \\
\hline \multirow{9}{*}{ Social } & \multirow{2}{*}{$\begin{array}{l}\text { Labor Practices and Decent } \\
\text { Work }\end{array}$} & Employment & 3 \\
\hline & & Occupational health and safety & 3 \\
\hline & Human Rights & Freedom of association and collective bargaining & 1 \\
\hline & Society & Local communities & 1 \\
\hline & Product Responsibility & - & - \\
\hline & \multirow{4}{*}{ Non-GRI indicators } & Food to energy competition & 1 \\
\hline & & Jobs created & 4 \\
\hline & & Job opportunities created & 2 \\
\hline & & Social benefits & 1 \\
\hline
\end{tabular}

Table 6 Single Criteria Optimization Approaches Used in Reviewed Papers.

\begin{tabular}{|l|c|l|c|}
\hline \multicolumn{1}{|c|}{ Article: } & Sustainability & \multicolumn{1}{c|}{ Indicators } & Modeling approach \\
\hline Nozick and Turnquist (2001) & Eco & $\begin{array}{l}\text { min. inventory cost } \\
\text { min. transportation cost }\end{array}$ & LP \\
\hline Timpe and Kallrath (2000) & Eco & max. sales & NLP \\
\hline Tsao and Lu (2012) & Eco & min. total network cost & $\begin{array}{l}\text { min. facility location cost } \\
\text { min. transportation costs } \\
\text { min. replenishment costs } \\
\text { min. safety stock costs }\end{array}$ \\
\hline You and Grossmann (2008) & Eco & $\begin{array}{l}\text { min. production cost } \\
\text { min. raw material ordering }\end{array}$ & HA \\
\hline Garcia-Herreros et al. (2014) & Eco & $\begin{array}{l}\text { min. investment costs min. distribution } \\
\text { cost }\end{array}$ & HA \\
\hline Oliveira et al. (2013) & Eco & $\begin{array}{l}\text { min. investment cost } \\
\text { min. logistics cost }\end{array}$ & HA \\
\hline S. Liu and Papageorgiou (2013) & Eco & $\begin{array}{l}\text { min. total costs } \\
\text { min. delivery lead time min. lost sales }\end{array}$ & MILP \\
\hline Chan and Chung (2004) & Eco & $\begin{array}{l}\text { min. total cost } \\
\text { min. delivery lead time } \\
\text { min. capacity utilization }\end{array}$ & GA \\
\hline Altiparmak et al. (2006) & Eco & $\begin{array}{l}\text { min. total cost } \\
\text { min. delivery lead time min. capacity } \\
\text { utilization }\end{array}$ & min. total cost \\
\hline Selim et al. (2008) & Eco & Eco & GA \\
\hline
\end{tabular}


Mujkić et al. : Sustainability and Optimization of Supply Chains: a Literature Review

Operations and Supply Chain Management 11(4) pp. 186 - 199 @ 2018

\begin{tabular}{|l|c|l|c|}
\hline \multicolumn{1}{|c|}{ Article: } & Sustainability & \multicolumn{1}{c|}{ Indicators } & Modeling approach \\
\hline & & $\begin{array}{l}\text { min. backlog level } \\
\text { max. profit }\end{array}$ & HA \\
\hline Min et al. (2006) & Eco & min. total costs & HA \\
\hline Nekooghadirli et al. (2014) & Eco & $\begin{array}{l}\text { min. total costs } \\
\text { min. delivery lead time }\end{array}$ & HA \\
\hline Azaron et al. (2008) & Eco & $\begin{array}{l}\text { min. total cost } \\
\text { min. cost variance }\end{array}$ \\
\hline
\end{tabular}

* Notes: LP - linear programming; MILP - mixed integer linear programming; NLP - nonlinear programming; MINLP - mixed integer nonlinear programming; GA generic algorithm; FA - fuzzy algorithm; HA - hybrid algorithm.

Eco - economic dimension of sustainability

Recently, companies have been pressured by governments and non-governmental organizations to reconsider their current business models and to endorse more sustainable and environmentally friendly SCs and business models. As a result, there is a growing interest and awareness of more environmentally and social friendly models among researchers and practitioners. As stated by Papageorgiou (2009) there is a need for an integrated economic, environmental and recently social (Eskandarpour et al., 2015) framework for sustainable SCs, which leads to multicriteria optimization and decision making models.

Table 7 Multi-criteria Optimization Models Used in Reviewed Papers.

\begin{tabular}{|c|c|c|c|}
\hline Article: & Sustainability & Indicators & Approach \\
\hline Wang et al. (2011) & Eco-Env & min. total cost & LP \\
\hline Tognetti et al. (2015) & Eco-Env & $\begin{array}{l}\max . \mathrm{NPV} \\
\min . \mathrm{CO}_{2} \text { emission }\end{array}$ & LP \\
\hline Mir Saman Pishvaee et al. (2011) & Eco-Env & min. total cost & MILP \\
\hline Alçada-Almeida et al. (2009) & Eco-Env-Soc & min. total cost & MILP \\
\hline Abdallah et al. (2012) & Eco-Env & $\begin{array}{l}\text { min. total costs } \\
\text { min. carbon trading cost }\end{array}$ & MILP \\
\hline Diabat et al. (2013) & Eco-Env & $\begin{array}{l}\text { min. total costs } \\
\text { min. carbon trading cost }\end{array}$ & MILP \\
\hline Elhedhli and Merrick (2012) & Eco-Env & $\begin{array}{l}\text { min. total costs } \\
\text { min. } \mathrm{CO}_{2} \text { emission }\end{array}$ & MILP \\
\hline Nurjanni et al. (2017) & Eco-Env & $\begin{array}{l}\text { min. total costs } \\
\text { min. } \mathrm{CO}_{2} \text { emission }\end{array}$ & MILP \\
\hline Varsei and Polyakovskiy (2017) & Eco-Env-Soc & $\begin{array}{l}\text { min. total costs } \\
\text { min. } \mathrm{CO}_{2} \text { emission } \\
\text { max. social benefits }\end{array}$ & MILP \\
\hline Kantas et al. (2015) & Eco-Env & $\begin{array}{l}\text { min. total cost } \\
\text { min. } \mathrm{CO}_{2} \text { emission } \\
\text { min. water usage }\end{array}$ & MILP \\
\hline Chen and Andresen (2014) & Eco-Env-Soc & $\begin{array}{l}\text { min. total cost } \\
\text { min. } \mathrm{CO}_{2} \text { emission } \\
\text { min. number of injuries }\end{array}$ & MILP \\
\hline Chaabane et al. (2012) & Eco-Env & $\begin{array}{l}\text { min. total cost } \\
\text { min. GHG emission }\end{array}$ & MILP \\
\hline Kostin et al. (2015) & Eco-Env & $\begin{array}{l}\text { min. total cost } \\
\text { min. GHG emission }\end{array}$ & MILP \\
\hline Zhang et al. (2014) & Eco-Env & $\begin{array}{l}\text { min. total costs } \\
\text { min. lead time } \\
\text { min. GHG emission }\end{array}$ & MILP \\
\hline Babazadeh et al. (2017) & Eco-Env & $\begin{array}{l}\text { min. total costs } \\
\text { min. environmental impact }\end{array}$ & MILP \\
\hline Mota et al. (2015) & Eco-Env-Soc & $\begin{array}{l}\text { min. total cost } \\
\text { min. environmental impact } \\
\text { max. jobs created }\end{array}$ & MILP \\
\hline Miret et al. (2016) & Eco-Env-Soc & $\begin{array}{l}\text { max. profit } \\
\text { min. environmental impact }\end{array}$ & MILP \\
\hline Santibañez-Aguilar et al. (2014) & Eco-Env-Soc & $\begin{array}{l}\text { max. profit } \\
\text { min. environmental impact } \\
\text { max. jobs created }\end{array}$ & MILP \\
\hline Z. Liu et al. (2014) & Eco-Env & $\begin{array}{l}\text { max. profit } \\
\text { min. GHG emission } \\
\text { min. fuel consumption }\end{array}$ & MILP \\
\hline Hugo and Pistikopoulos (2005) & Eco-Env & $\begin{array}{l}\text { max. NPV } \\
\text { min. environmental impact }\end{array}$ & MILP \\
\hline Bojarski et al. (2009) & Eco-Env & $\max . \mathrm{NPV}$ & MILP \\
\hline
\end{tabular}




\begin{tabular}{|c|c|c|c|}
\hline Article: & Sustainability & Indicators & Approach \\
\hline & & min. environmental impact & \\
\hline Pérez-Fortes et al. (2012) & Eco-Env-Soc & $\begin{array}{l}\text { max. NPV } \\
\text { min. environmental impact }\end{array}$ & MILP \\
\hline You et al. (2012) & Eco-Env-Soc & $\begin{array}{l}\text { max. NPV } \\
\text { max. GHG emission saving } \\
\text { max. jobs created }\end{array}$ & MILP \\
\hline Cambero and Sowlati (2016) & Eco-Env-Soc & $\begin{array}{l}\text { max. NPV } \\
\text { max. GHG emission saving } \\
\text { max. jobs created }\end{array}$ & MILP \\
\hline Lira-Barragán et al. (2010) & Eco-Env & $\begin{array}{l}\text { min. total costs } \\
\text { max. water quality }\end{array}$ & MINLP \\
\hline Garg et al. (2015) & Eco-Env & $\begin{array}{l}\text { max. profit } \\
\text { min. environmental impact }\end{array}$ & MINLP \\
\hline Lee et al. (2009) & Eco-Env & min. total costs & GA \\
\hline Yeh and Chuang (2011) & Eco-Env & $\begin{array}{l}\text { min. total costs } \\
\text { min. environmental impact }\end{array}$ & GA \\
\hline Amin and Zhang (2012) & Eco-Env & $\begin{array}{l}\text { max. profit } \\
\text { min. products defect }\end{array}$ & GA \\
\hline Saffari et al. (2015) & Eco-Env-Soc & $\begin{array}{l}\text { min. total costs } \\
\text { min. } \mathrm{CO}_{2} \text { emission } \\
\text { max. jobs created }\end{array}$ & GA \\
\hline Dehghanian and Mansour (2009) & Eco-Env-Soc & $\begin{array}{l}\text { max. profit } \\
\text { min. environmental impact } \\
\text { max. social benefits }\end{array}$ & GA \\
\hline M. S. Pishvaee et al. (2012) & Eco-Env & $\begin{array}{l}\text { min. total cost } \\
\text { min. } \mathrm{CO}_{2} \text { emission }\end{array}$ & FA \\
\hline Özkır and Başlıgil (2013) & Eco-Env & $\begin{array}{l}\text { max. profit, } \\
\text { consumer satisfaction } \\
\text { and trade level }\end{array}$ & FA \\
\hline Chibeles-Martins et al. (2016) & Eco-Env & $\begin{array}{l}\text { max. profit } \\
\text { min. environmental impact }\end{array}$ & FA \\
\hline Amin and Zhang (2013) & Eco-Env & min. total costs & $\mathrm{HA}$ \\
\hline Ruiz-Femenia et al. (2013) & Eco-Env & $\begin{array}{l}\max . N P V \\
\min . \text { GWP }\end{array}$ & $\mathrm{HA}$ \\
\hline
\end{tabular}

* Notes: LP - linear programming; MILP - mixed integer linear programming; NLP - nonlinear programming; MINLP - mixed integer nonlinear programming; GA generic algorithm; FA - fuzzy algorithm; HA - hybrid algorithm.

Eco - economic dimension of sustainability, Env environmental dimension of sustainability, Soc - social dimension of sustainability

Papers reviewed in this work and their application in sustainable SCs are divided into four categories, shown in Table 8. The first category, sustainability-includes all three dimensions; Second category, network structure-covers and closed loops SCs dealing with both forward and reverse flow respectively; Third category, logistics-includes transportation and inventory management issues; Fourth category, uncertainties-covers SC management issues.

* Notes: LP - linear programming; MILP - mixed integer linear programming; NLP - nonlinear programming; MINLP - mixed integer nonlinear programming; GA generic algorithm; FA - fuzzy algorithm; HA - hybrid algorithm.

While sustainability is the focus of this paper, the reviewed articles studied other aspects of SCs besides sustainability. It can be seen that network structure, logistics, and uncertainties in SCs are commonly studied areas.

Table 8 Application of mathematical modeling approaches in SCs.

\begin{tabular}{|c|c|c|c|c|c|c|c|c|}
\hline \multicolumn{2}{|c|}{$\begin{array}{ll}\text { Application } & \text { Modeling approach } \\
\end{array}$} & LP & MILP & NLP & MINLP & GA & $\mathrm{FA}$ & $\mathrm{HA}$ \\
\hline \multirow{3}{*}{ Sustainability } & Economic & $\bullet$ & $\bullet$ & $\bullet$ & $\bullet$ & $\bullet$ & $\bullet$ & $\bullet$ \\
\hline & Environmental & $\bullet$ & $\bullet$ & & $\bullet$ & $\bullet$ & $\bullet$ & $\bullet$ \\
\hline & Social & & $\bullet$ & & $\bullet$ & $\bullet$ & & \\
\hline \multirow{3}{*}{ Network structure } & Open loop SC & & $\bullet$ & & & & & \\
\hline & Closed loop SC & & $\bullet$ & & $\bullet$ & & $\bullet$ & \\
\hline & Facility location & & & $\bullet$ & $\bullet$ & & $\bullet$ & \\
\hline \multirow{2}{*}{ Logistic in SC } & Transportation & & $\bullet$ & & & & & \\
\hline & Inventory management & & & & & & & $\bullet$ \\
\hline \multirow{4}{*}{ Uncertainty } & Demand & & $\bullet$ & & $\bullet$ & $\bullet$ & $\bullet$ & $\bullet$ \\
\hline & Returned products & & $\bullet$ & & & & & $\bullet$ \\
\hline & Supplies & & & & $\bullet$ & & $\bullet$ & \\
\hline & Costs & & $\bullet$ & & $\bullet$ & & $\bullet$ & \\
\hline
\end{tabular}




\section{DISCUSSION AND FUTURE RESEARCH DIRECTIONS}

The objective of this study was to analyze literature of optimization techniques in sustainable SCs published in peer-reviewed journals. The present study was organized along three research questions: 1) which sustainability dimensions are considered in each article? 2) Which sustainability aspects of SC are covered by mathematical models? 3) What objectives and how mathematical models for sustainable SCs are formulated?

As shown in Figure 2 and Figure 3, the number of papers published in peer-reviewed journals is increasing. Therefore, we can conclude that the interest of scholars in SCs sustainability, SCM and SC optimization is growing. Furthermore, Table 1 shows that a wide range of topics have been covered in reviewed papers, during past 17 years.

\subsection{Sustainable Supply Chains}

Sustainable SCs and SCM have received a great deal of interest from scholars (see Figure 2 and Figure 3). Sustainability is commonly represented with three aspects, namely: Economic sustainable development is the ability to support a positive wealth system over time. Environmental friendliness is the capability to live and acquire resources from nature, with minimal negative impacts. Social equality is the long-term goal of gap reduction including wealth, health, and human rights between different groups of people within the society.

From Figure $\mathbf{4}$ it is evident that economic development and economic indicators have received most attention from scholars and managers. This is a consequence of traditional SCs being business oriented (economic development is prioritized). However, in recent years there is a strong tendency towards more environmentally and socially responsible SC. Environmental sustainability is often incorporated with economic aspect of SCs into multi-objective models or as variable constraint (e.g., $\mathrm{CO}_{2}$ emission, $\mathrm{GHG}$ footprint). While there are numerous environmental indicators used, they are mostly combined with cost minimization. Cost is often used because SCs involve material flow within a network structure, which involves various costs (e.g., logistics, operating). Incorporating environmental and economic sustainability can bring operating benefits and strategic benefits such as higher profits, reduced waste (recycling and remanufacturing), increased brand and image awareness. Social sustainability is mostly combined with economic and environmental sustainability into multiobjective mathematical models, and mostly employment and job creation indicators are used as the objective function. While social aspect is the least studied it can have significant benefits (e.g., improved human rights, unemployment reduction, and improved working conditions). Future research should include other social indicators beyond employment and job creation.

\subsection{Supply Chain Sustainability and Optimization \\ A large number of optimization techniques are used to} address different SC sustainability issues, where mostly reviewed papers used mixed-integer programming either as linear or nonlinear problems. In this work, we reviewed 50 papers, among which 14 have studied only economic aspects of SCs. Other 25 papers studied a combination of economic and environmental aspects of sustainability as an aggregated objective. The remaining 11 papers considered all three dimensions of sustainability.

All reviewed papers are grouped based on decision criteria. Some models consider only economic aspects of $\mathrm{SCs}$, either as single or multi-objective problems and they are classified under single criterion models (see Table 6). However, most models consider two or more sustainability dimensions aggregating single or multi-objective models (see Table 7).

\subsection{Limitation and Future Research Directions}

It is important to point out some of the limitations of this study. First, this study was carried out using Science Direct database, which may have limited the search results. However, most SC and SCM journals and published papers are indexed by this database. Second, the search included only papers published in peer-reviewed journals, while extending the search to include conference papers, books, and dissertations might change the specific results. However, we believe that the overall trends and results would remain the same. Third, the search timeframe is from 2000 until 2017, which excluded earlier papers. This limited search for papers deals especially with economic sustainability. However, this is evident only in case of papers dealing with economic sustainability, while papers dealing with environmental and social aspects of sustainability are thoughtfully included.

Based on the limitations and findings in this paper, we suggest some research directions for future research within the field of sustainable SCs and SC optimization. Firstly, although there are papers dealing with all the three dimensions of sustainability, there is a lack of models dealing with social sustainability beyond employment indicators. Even though economic and environmental sustainability is extensively studied, most mathematical models used direct environmental impact (GHG emission, climate change, resources depletion) and economic models mostly used money flows as objective functions. However, future research should incorporate indicators such as green technology, carbon trading and closing the loop of SCs, which can have enormous environmental and economic impacts.

\section{CONCLUSION}

The interest in economic sustainability is a reflection of traditional business values as they stand for profit maximization. Furthermore, most economic indicators are related to profit growth and cost reduction, which are longterm decision-making goals. Integration of environmental criteria in SC sustainability into mathematical models is mostly done through aggregated indicators, among which Eco-indicator 99 is the most commonly used. Additionally, 
most indicators measure direct impact on environment and are linked to long term decisions. Social sustainability is far less present in quantitative research than economic and environmental dimensions. One reason that can explain this lack of papers in social aspect, is that most social indicators are difficult to quantify, and it is challenging to incorporate them into mathematical models. Another reason is that there is lack of data related to social development and human rights. This might be due to the sensitivity of social indicators, which further increases difficulties in collecting and implementing social indicators into mathematical models. Currently, most reviewed papers used employment metrics with slight variations as a social indicator, while impacts on human rights, society and products still remain less commonly used. However, interest in social sustainability is growing.

In sum, a large number of modeling approaches are used to address sustainability problems in SCs and the most used techniques are MIP with linear and non-linear variations. Certain models address only economic sustainability, either as a single or multi-objective models. The rest of papers have incorporated either two or three dimensions of sustainability into mathematical models. Numerous optimization techniques are used in wide variety of issues including sustainability, network structure, logistics, and uncertainties in SCs.

\section{ACKNOWLEDGEMENTS}

The authors are grateful for financial support from Sigma Agile, a part of the Erasmus Mundus Action 2 scholarship program. The authors thank Peter Jones for his help with the English language.

\section{REFERENCES}

Abdallah, T., Farhat, A., Diabat, A., \& Kennedy, S. (2012). Green Supply Chains with Carbon Trading and Environmental Sourcing: Formulation and Life Cycle Assessment. Applied Mathematical Modelling, 36(9), pp. 4271-4285.

Al Ansari, M. S. (2012). A Review of Optimal Designs in Relation to Supply Chains and Sustainable Chemical Processes. Modern Applied Science, 6(12).

Alçada-Almeida, L., Coutinho-Rodrigues, J., \& Current, J. (2009). A Multiobjective Modeling Approach to Locating Incinerators. Socio-Economic Planning Sciences, 43(2), pp. 111-120.

Altiparmak, F., Gen, M., Lin, L., \& Paksoy, T. (2006). A Genetic Algorithm Approach for MultiObjective Optimization of Supply Chain Networks. Computers \& Industrial Engineering, 51(1), pp. 196-215.

Amin, S. H., \& Zhang, G. (2012). An Integrated Model for Closed-Loop Supply Chain Configuration and Supplier Selection: Multi-Objective Approach. Expert Systems with Applications, 39(8), pp. 6782-6791.

Amin, S. H., \& Zhang, G. (2013). A Multi-Objective Facility Location Model for Closed-Loop Supply Chain Network under Uncertain Demand and
Return. Applied Mathematical Modelling, 37(6), pp. 4165-4176.

Azaron, A., Brown, K. N., Tarim, S. A., \& Modarres, M. (2008). A Multi-Objective Stochastic Programming Approach for Supply Chain Design Considering Risk. International Journal of Production Economics, 116(1), pp. 129-138.

Babazadeh, R., Razmi, J., Pishvaee, M. S., \& Rabbani, M. (2017). A Sustainable Second-Generation Biodiesel Supply Chain Network Design Problem under Risk. Omega, 66, pp. 258-277.

Barbosa-Póvoa, A. P. (2012). Progresses and Challenges in Process Industry Supply Chains Optimization. Current Opinion in Chemical Engineering, 1(4), pp. 446-452.

Barbosa-Póvoa, A. P. (2014). Process Supply Chains Management Â€“ Where Are We? Where to Go Next? Frontiers in Energy Research, 2.

Basnet, C., \& Seuring, S. (2014). Demand-Oriented Supply Chain Strategies-a Review of the Literature.

Benoît, C. (2010). Guidelines for Social Life Cycle Assessment of Products: UNEP/Earthprint.

Bhinge, R., Moser, R., Moser, E., Lanza, G., \& Dornfeld, D. (2015). Sustainability Optimization for Global Supply Chain Decision-Making. Procedia CIRP, 26, pp. 323-328.

Bojarski, A. D., Laínez, J. M., Espuña, A., \& Puigjaner, L. (2009). Incorporating Environmental Impacts and Regulations in a Holistic Supply Chains Modeling: An Lca Approach. Computers \& Chemical Engineering, 33(10), pp. 1747-1759.

Burritt, R., \& Schaltegger, S. (2014). Accounting Towards Sustainability in Production and Supply Chains. The British Accounting Review, 46(4), pp. 327-343.

Cambero, C., \& Sowlati, T. (2016). Incorporating Social Benefits in Multi-Objective Optimization of Forest-Based Bioenergy and Biofuel Supply Chains. Applied Energy, 178, pp. 721-735.

Chaabane, A., Ramudhin, A., \& Paquet, M. (2012). Design of Sustainable Supply Chains under the Emission Trading Scheme. International Journal of Production Economics, 135(1), pp. 37-49.

Chan, F. T. S., \& Chung, S. H. (2004). A MultiCriterion Genetic Algorithm for Order Distribution in a Demand Driven Supply Chain. International Journal of Computer Integrated Manufacturing, 17(4), pp. 339-351.

Chen, Z., \& Andresen, S. (2014). A Multiobjective Optimization Model of Production-Sourcing for Sustainable Supply Chain with Consideration of Social, Environmental, and Economic Factors. Mathematical Problems in Engineering, 2014, pp $1-11$.

Chibeles-Martins, N., Pinto-Varela, T., Barbosa-Póvoa, A. P., \& Novais, A. Q. (2016). A Multi-Objective Meta-Heuristic Approach for the Design and Planning of Green Supply Chains - Mbsa. Expert Systems with Applications, 47, pp. 71-84.

Croom, S., Romano, P., \& Giannakis, M. (2000). Supply Chain Management: An Analytical 
Framework for Critical Literature Review. European Journal of Purchasing \& Supply Management, 6(1), pp. 67-83.

Dehghanian, F., \& Mansour, S. (2009). Designing Sustainable Recovery Network of End-of-Life Products Using Genetic Algorithm. Resources, Conservation and Recycling, 53(10), pp. 559-570.

Diabat, A., Abdallah, T., Al-Refaie, A., Svetinovic, D., \& Govindan, K. (2013). Strategic Closed-Loop Facility Location Problem with Carbon Market Trading. IEEE Transactions on engineering Management, 60(2), pp. 398-408.

Elhedhli, S., \& Merrick, R. (2012). Green Supply Chain Network Design to Reduce Carbon Emissions. Transportation Research Part D: Transport and Environment, 17(5), pp. 370-379.

Elkington, J. (2001). Enter the Triple Bottom Line. 2001. http://www. johnelkington. com/TBLelkington-chapter. pdf. Acesso em, 11, pp. 12.

Eskandarpour, M., Dejax, P., Miemczyk, J., \& Péton, O. (2015). Sustainable Supply Chain Network Design: An Optimization-Oriented Review. Omega, 54, pp. 11-32.

Ganeshan, R., \& Harrison, T. P. (1995). An Introduction to Supply Chain Management. Department of Management Science and Information Systems, Penn State University, pp. 27.

Garcia-Herreros, P., Wassick, J. M., \& Grossmann, I. E. (2014). Design of Resilient Supply Chains with Risk of Facility Disruptions. Industrial \& Engineering Chemistry Research, 53(44), pp. 17240-17251.

Garg, K., Kannan, D., Diabat, A., \& Jha, P. C. (2015). A Multi-Criteria Optimization Approach to Manage Environmental Issues in Closed Loop Supply Chain Network Design. Journal of Cleaner Production, 100, pp. 297-314.

Giddings, B., Hopwood, B., \& O'brien, G. (2002). Environment, Economy and Society: Fitting Them Together into Sustainable Development. Sustainable development, 10(4), pp. 187-196.

GRI, G. R. I. (2014). G4 Sustainability Reporting Guidelines, 2013.

Grossmann, I. E. (2004). Challenges in the New Millennium: Product Discovery and Design, Enterprise and Supply Chain Optimization, Global Life Cycle Assessment. Computers \& Chemical Engineering, 29(1), pp. 29-39.

Grossmann, I. E. (2012). Advances in Mathematical Programming Models for Enterprise-Wide Optimization. Computers \& Chemical Engineering, 47, pp. 2-18.

Gunasekaran, A., Patel, C., \& Tirtiroglu, E. (2001). Performance Measures and Metrics in a Supply Chain Environment. International journal of operations \& production Management, 21(1/2), pp. 71-87.

Harris, J. M. (2000). Basic Principles of Sustainable Development.

Hugo, A., \& Pistikopoulos, E. N. (2005). Environmentally Conscious Long-Range Planning and Design of Supply Chain Networks. Journal of Cleaner Production, 13(15), pp. 1471-1491.

Jamshidi, R., Fatemi Ghomi, S. M. T., \& Karimi, B. (2012). Multi-Objective Green Supply Chain Optimization with a New Hybrid Memetic Algorithm Using the Taguchi Method. Scientia Iranica, 19(6), pp. 1876-1886

Kantas, A. B., Cobuloglu, H. I., \& Büyüktahtakın, İ. E. (2015). Multi-Source Capacitated Lot-Sizing for Economically Viable and Clean Biofuel Production. Journal of Cleaner Production, 94, pp. 116-129.

Kostin, A., Guillén-Gosálbez, G., \& Jiménez, L. (2015). Dimensionality Reduction Applied to the Simultaneous Optimization of the Economic and Life Cycle Environmental Performance of Supply Chains. International Journal of Production Economics, 159, pp. 223-232.

Lababidi, H. M., Ahmed, M. A., Alatiqi, I. M., \& AlEnzi, A. F. (2004). Optimizing the Supply Chain of a Petrochemical Company under Uncertain Operating and Economic Conditions. Industrial \& Engineering Chemistry Research, 43(1), pp. 63-73.

Lee, J.-E., Gen, M., \& Rhee, K.-G. (2009). Network Model and Optimization of Reverse Logistics by Hybrid Genetic Algorithm. Computers \& Industrial Engineering, 56(3), pp. 951-964.

Lira-Barragán, L. F., Ponce-Ortega, J. M. a., SernaGonzález, M., \& El-Halwagi, M. M. (2010). An Minlp Model for the Optimal Location of a New Industrial Plant with Simultaneous Consideration of Economic and Environmental Criteria. Industrial \& Engineering Chemistry Research, 50(2), pp. 953-964.

Liu, S., \& Papageorgiou, L. G. (2013). Multiobjective Optimisation of Production, Distribution and Capacity Planning of Global Supply Chains in the Process Industry. Omega, 41(2), pp. 369-382.

Liu, Z., Qiu, T., \& Chen, B. (2014). A Study of the Lca Based Biofuel Supply Chain Multi-Objective Optimization Model with Multi-Conversion Paths in China. Applied Energy, 126, pp. 221-234.

Meixell, M. J., \& Gargeya, V. B. (2005). Global Supply Chain Design: A Literature Review and Critique. Transportation Research Part E: Logistics and Transportation Review, 41(6), pp. 531-550.

Melo, M. T., Nickel, S., \& Saldanha-da-Gama, F. (2009). Facility Location and Supply Chain Management - a Review. European Journal of Operational Research, 196(2), pp. 401-412.

Min, H., Ko, C. S., \& Ko, H. J. (2006). The Spatial and Temporal Consolidation of Returned Products in a Closed-Loop Supply Chain Network. Computers \& Industrial Engineering, 51(2), pp. 309-320.

Min, H., \& Zhou, G. (2002). Supply Chain Modeling: Past, Present and Future. Computers \& Industrial Engineering, 43(1), pp. 231-249.

Miret, C., Chazara, P., Montastruc, L., Negny, S., \& Domenech, S. (2016). Design of Bioethanol Green Supply Chain: Comparison between First and Second Generation Biomass Concerning Economic, Environmental and Social Criteria. 
Computers \& Chemical Engineering, 85, pp. 1635.

Mota, B., Gomes, M. I., Carvalho, A., \& BarbosaPovoa, A. P. (2015). Towards Supply Chain Sustainability: Economic, Environmental and Social Design and Planning. Journal of Cleaner Production, 105, pp. 14-27.

Nekooghadirli, N., Tavakkoli-Moghaddam, R., Ghezavati, V. R., \& Javanmard, S. (2014). Solving a New Bi-Objective Location-Routing-Inventory Problem in a Distribution Network by MetaHeuristics. Computers \& Industrial Engineering, 76, pp. 204-221.

Ness, B., Urbel-Piirsalu, E., Anderberg, S., \& Olsson, L. (2007). Categorising Tools for Sustainability Assessment. Ecological Economics, 60(3), pp. 498-508.

Nozick, L. K., \& Turnquist, M. A. (2001). Inventory, Transportation, Service Quality and the Location of Distribution Centers. European Journal of Operational Research, 129(2), pp. 362-371.

Nurjanni, K. P., Carvalho, M. S., \& Costa, L. (2017). Green Supply Chain Design: A Mathematical Modeling Approach Based on a Multi-Objective Optimization Model. International Journal of Production Economics, 183, pp. 421-432.

Oliveira, F., Gupta, V., Hamacher, S., \& Grossmann, I. E. (2013). A Lagrangean Decomposition Approach for Oil Supply Chain Investment Planning under Uncertainty with Risk Considerations. Computers \& Chemical Engineering, 50, pp. 184-195.

Özkır, V., \& Başlıgil, H. (2013). Multi-Objective Optimization of Closed-Loop Supply Chains in Uncertain Environment. Journal of Cleaner Production, 41, pp. 114-125.

Papageorgiou, L. G. (2009). Supply Chain Optimisation for the Process Industries: Advances and Opportunities. Computers \& Chemical Engineering, 33(12), pp. 1931-1938.

Pérez-Fortes, M., Laínez-Aguirre, J. M., Arranz-Piera, P., Velo, E., \& Puigjaner, L. (2012). Design of Regional and Sustainable Bio-Based Networks for Electricity Generation Using a Multi-Objective Milp Approach. Energy, 44(1), pp. 79-95.

Pishvaee, M. S., Rabbani, M., \& Torabi, S. A. (2011). A Robust Optimization Approach to Closed-Loop Supply Chain Network Design under Uncertainty. Applied Mathematical Modelling, 35(2), pp. 637649.

Pishvaee, M. S., Razmi, J., \& Torabi, S. A. (2012). Robust Possibilistic Programming for Socially Responsible Supply Chain Network Design: A New Approach. Fuzzy Sets and Systems, 206, pp. $1-20$.

Rowley, J., \& Slack, F. (2004). Conducting a Literature Review. Management research news, 27(6), pp. 31-39.

Ruiz-Femenia, R., Guillén-Gosálbez, G., Jiménez, L., \& Caballero, J. A. (2013). Multi-Objective Optimization of Environmentally Conscious Chemical Supply Chains under Demand
Uncertainty. Chemical Engineering Science, 95, pp. 1-11.

Saffari, H., Makui, A., Mahmoodian, V., \& Pishvaee, M. S. (2015). Multi-Objective Robust Optimization Model for Social Responsible Closed-Loop Supply Chain Solved by NonDominated Sorting Genetic Algorithm. Journal of Industrial and Systems Engineering, 8(3), pp. $42-$ 58.

Sahinidis, N. V. (2004). Optimization under Uncertainty: State-of-the-Art and Opportunities. Computers \& Chemical Engineering, 28(6-7), pp. 971-983.

Santibañez-Aguilar, J. E., González-Campos, J. B., Ponce-Ortega, J. M., Serna-González, M., \& ElHalwagi, M. M. (2014). Optimal Planning and Site Selection for Distributed Multiproduct Biorefineries Involving Economic, Environmental and Social Objectives. Journal of Cleaner Production, 65, pp. 270-294.

Selim, H., Araz, C., \& Ozkarahan, I. (2008). Collaborative Production-Distribution Planning in Supply Chain: A Fuzzy Goal Programming Approach. Transportation Research Part E: Logistics and Transportation Review, 44(3), pp. 396-419.

Seuring, S., \& Müller, M. (2008). From a Literature Review to a Conceptual Framework for Sustainable Supply Chain Management. Journal of Cleaner Production, 16(15), pp. 1699-1710.

Shah, N. (2005). Process Industry Supply Chains: Advances and Challenges. Computers \& Chemical Engineering, 29(6), pp. 1225-1235.

Srivastava, S. K. (2007). Green Supply-Chain Management: A State-of-the-Art Literature Review. International Journal of Management Reviews, 9(1), pp. 53-80.

Tajbakhsh, A., \& Hassini, E. (2015). Performance Measurement of Sustainable Supply Chains: A Review and Research Questions. International Journal of Productivity and Performance Management, 64(6), pp. 744-783.

Timpe, C. H., \& Kallrath, J. (2000). Optimal Planning in Large Multi-Site Production Networks. European Journal of Operational Research, 126(2), pp. 422-435.

Tognetti, A., Grosse-Ruyken, P. T., \& Wagner, S. M. (2015). Green Supply Chain Network Optimization and the Trade-Off between Environmental and Economic Objectives. International Journal of Production Economics, 170, pp. 385-392.

Trisna, T., Marimin, M., Arkeman, Y., \& Sunarti, T. C. (2016). Multi-Objective Optimization for Supply Chain Management Problem: A Literature Review. Decision Science Letters, pp. 283-316.

Tsao, Y.-C., \& Lu, J.-C. (2012). A Supply Chain Network Design Considering Transportation Cost Discounts. Transportation Research Part E: Logistics and Transportation Review, 48(2), pp. 401-414. 
Varsei, M., \& Polyakovskiy, S. (2017). Sustainable Supply Chain Network Design: A Case of the Wine Industry in Australia. Omega, 66, pp. 236247.

Vidal, C. J., \& Goetschalckx, M. (1997). Strategic Production-Distribution Models: A Critical Review with Emphasis on Global Supply Chain Models. European Journal of Operational Research, 98(1), pp. 1-18.

Wang, F., Lai, X., \& Shi, N. (2011). A Multi-Objective Optimization for Green Supply Chain Network Design. Decision Support Systems, 51(2), pp. 262269.

Wolf, M.-A., Pant, R., Chomkhamsri, K., Sala, S., \& Pennington, D. (2012). The International Reference Life Cycle Data System (Ilcd) Handbook-Jrc Reference Reports.

Yeh, W.-C., \& Chuang, M.-C. (2011). Using MultiObjective Genetic Algorithm for Partner Selection in Green Supply Chain Problems. Expert Systems with Applications, 38(4), pp. 4244-4253.

You, F., \& Grossmann, I. E. (2008). Mixed-Integer Nonlinear Programming Models and Algorithms for Large-Scale Supply Chain Design with Stochastic Inventory Management. Industrial \& Engineering Chemistry Research, 47(20), pp. $7802-7817$.

You, F., Tao, L., Graziano, D. J., \& Snyder, S. W. (2012). Optimal Design of Sustainable Cellulosic Biofuel Supply Chains: Multiobjective Optimization Coupled with Life Cycle Assessment and Input-Output Analysis. AIChE Journal, 58(4), pp. 1157-1180.

Zhang, Q., Shah, N., Wassick, J., Helling, R., \& van Egerschot, P. (2014). Sustainable Supply Chain Optimisation: An Industrial Case Study. Computers \& Industrial Engineering, 74, pp. 6883.

Zlatan Mujkić is a PhD student at department of industrial Engineering and Management at Lappeenranta University of Technology, Finland. He received his B.Sc. and M.Sc. at University of Tuzla, Bosnia and Herzegovina. His research interests include mathematical modeling, supply chain management, supply chain performance measurement and optimization.

Ardian Qorri is currently pursuing his $\mathrm{PhD}$ in Industrial Engineering and Management at Lappeenranta University of Technology, Finland. He received two B.Sc. degrees, one in Computer Sciences and one in Management and Informatics, from University of Pristina, Kosovo. He received his M.Sc. from University of Pristina and from University of Antwerp, Belgium. His research interest includes Performance Measurement and Optimization, Sustainable Supply Chain Management, Meta-analysis, and Multi Criteria Decision-Making methods.

Andrzej Kraslawski is a professor of System Engineering at Lappeenranta University of technology and professor at Technical University of Lodz. He has a PhD degree in Chemical Engineering from Technical University of Lodz, Poland and is a visiting professor at several universities. He has published over 200 papers in various international journals and conferences. He serves as a reviewer and was on editorial board in several international journals. His current research included supply chain management and sustainably, performance measurement and optimization of supply chain and supply chain of critical materials. 